\title{
Family function fully mediates the relationship between social support and perinatal depression in rural Southwest China
}

Yilin Huang ${ }^{1+}$, Yan Liü ${ }^{1+}$, Yu Wang ${ }^{2}$ and Danping Liü ${ }^{1 *}$

\begin{abstract}
Background: Perinatal depression is the most common complication of gestation and childbearing affecting women and their families, and good social support and family function are considered protective and modifiable factors. This study aimed to investigate depression status and explore inter-relationships between social support and perinatal depression considering the influence of family function in rural areas of Southwest China.

Methods: This is a cross-sectional study. The following instruments were used: the Edinburgh Postpartum Depression Scale, the APGAR Family Care Index Scale, and the Social Support Rate Scale. A structural equation modelling was used to test the hypothesis relationships among the variables.

Results: A total of 490 rural antenatal $(N=249)$ and postpartum $(N=241)$ women (mean age (standard deviation), $28.17 \pm 5.12$ ) participated. We found that the prevalence of depression symptoms was $10.4 \%$. Path analysis showed that family function had a direct negative correlation with depression ( $\beta=-0.251,95 \% \mathrm{Cl}:-0.382$ to -0.118$)$. Social support had a direct positive correlation with family function ( $\beta=0.293,95 \% \mathrm{Cl}: 0.147$ to 0.434$)$ and had an indirect negative correlation with depression ( $\beta=-0.074,95 \% \mathrm{Cl}$ : 0.139 to -0.032 ), family function fully mediated the relationship between social support and depression.

Conclusions: Findings of this study highlight that family function should be considered as the key target for interventions aiming to lower the prevalence of perinatal depression. Family members interventions are critical to reduce depression among antenatal and postpartum women.
\end{abstract}

Keywords: Social support, Family function, Perinatal depression, Rural China

\footnotetext{
*Correspondence: liudanping03@163.com

${ }^{\dagger}$ Yilin Huang and Yan Liu contributed equally to this work.

'West China School of Public Health and West China Fourth Hospital,

Sichuan University, Chengdu 610041, China

Full list of author information is available at the end of the article
}

(c) The Author(s). 2021 Open Access This article is licensed under a Creative Commons Attribution 4.0 International License, which permits use, sharing, adaptation, distribution and reproduction in any medium or format, as long as you give appropriate credit to the original author(s) and the source, provide a link to the Creative Commons licence, and indicate if changes were made. The images or other third party material in this article are included in the article's Creative Commons licence, unless indicated otherwise in a credit line to the material. If material is not included in the article's Creative Commons licence and your intended use is not permitted by statutory regulation or exceeds the permitted use, you will need to obtain permission directly from the copyright holder. To view a copy of this licence, visit http://creativecommons.org/licenses/by/4.0/. The Creative Commons Public Domain Dedication waiver (http://creativecommons.org/publicdomain/zero/1.0/) applies to the data made available in this article, unless otherwise stated in a credit line to the data. 


\section{Background}

The perinatal period is an important time of family transition for women and is associated with an increase in the onset of new or recurrent mental disorders. Depression and anxiety are the most common mental disorders experienced during the perinatal period [1,2]. Perinatal depression is of concern not only because of the suffering and distress it causes for women but also because of the risk of adverse effects on the developing foetus and child [3, 4].

The prevalence of perinatal depression in China has been estimated at $16.3 \%$ in a recent meta-analysis, with trends suggesting an increasing prevalence over the last decade and in less developed regions [5]. Perinatal depression usually has its onset during the third trimester of pregnancy or in the postpartum, affecting one in seven women $[6,7]$. The prevalence of antenatal depression is $19.7 \%$ in China [5]; this can be partly explained by the negative effects of psychosocial changes during pregnancy as well as various hormonal factors [8-10]. The prevalence of postpartum depression is $14.8 \%$ in China and there is a rising trend thereof [5]. A study has shown that women were more vulnerable to psychiatric illness after birth [11].

Women with antenatal depression appear to be at considerably higher risk of several negative outcomes: selfharm or suicide; failure to seek prenatal care; and, poor diet $[12,13]$. In turn, this may lead to adverse pregnancy outcomes such as complications during pregnancy, premature birth, dysplasia of the foetus and low infant birth weight $[14,15]$.. Additionally, postpartum depression is also associated with shorter breastfeeding duration [16] and may also be a risk factor for low social capacity in children [17]. Existing literature shows that factors associated with pregnancy and postpartum depression mainly include socio-demographic characteristics including maternal age, marital status, education, income and complications of pregnancy $[15,18-20]$ as well as social support [21], and family function [22].

Social support is defined as instrumental, informational, and emotional support provided by a social network including family, friends, and neighbourhoods, which can safeguard psychological well-being through buffering the effects of traumatic life events [23]. It can be characterised by the provider of support, including support from a spouse, relatives, or friends, with each thought to have independent protective effects against depression [24]. Social support as a protective and modifiable factor has been well investigated in relation to antenatal or postpartum depression [25]. Some studies have also shown that low-levels of social support were risk factors for perinatal depression [26, 27]. With adequate support, family ties will strengthen as has been shown in studies by Tarkka et al. (2003) and Lepistöet al.
(2017) which regard social support as an important resource to improve family functioning $[28,29]$.

Family functioning can be defined as the degree to which a family performs as a unit to manage conditions, activities, external stimuli, or events that cause stress [30]. Compared to healthy families, families with family dysfunction are characterised by having lower cohesion, lower warmth, and lower expressiveness but also higher conflict, rigidity, and affectionless control [22]. Previous studies have shown that depression is negatively correlated with family functioning [31, 32]. A study undertaken in China demonstrated that stronger family support can help improve the mental health of pregnant women [33]. In addition, Wang et al. (2019) proposed a model that family function moderated the indirect relationship between social support and depression among the elderly [34].

The availability of mental health resources in rural areas of China is low [35]. Studies have shown that living in rural areas of China is very significantly associated with perinatal depression [36]. Despite previous studies which have demonstrated the relationship between family function and depression as well as social support and depression, few studies have included these three variables in one study. We do so here in order to understand the interrelationships and potential mechanisms of social support, family function, and perinatal depression. We examined the influence of social support and family function on perinatal depression in rural areas of southwest China in this study. Based on the above description, we hypothesise a single mediator model as shown in Fig. 1. Specifically, social support would be positively associated with family function (Hypothesis 1) and negatively associated with depression (Hypothesis 2). We also hypothesise that family function would be negatively associated with depression (Hypothesis 3). Furthermore, we suggested that the relationship between social support and depression would be mediated by the family function (Hypothesis 4). The study aims to assess the prevalence of perinatal depression in rural China and to identify key factors including social support and family function which contribute to the prevention and control of perinatal depression.

\section{Methods \\ Participants and procedure}

This cross-sectional study was conducted among pregnant and postpartum women in rural areas of Sichuan Province, Southwest China, from December 2017 to May 2018. The optimal time to conduct the first screen for postpartum depression is within 6 months postpartum $[37,38]$. Therefore the target population in this study was the women who were pregnant or within 6 months postpartum. 


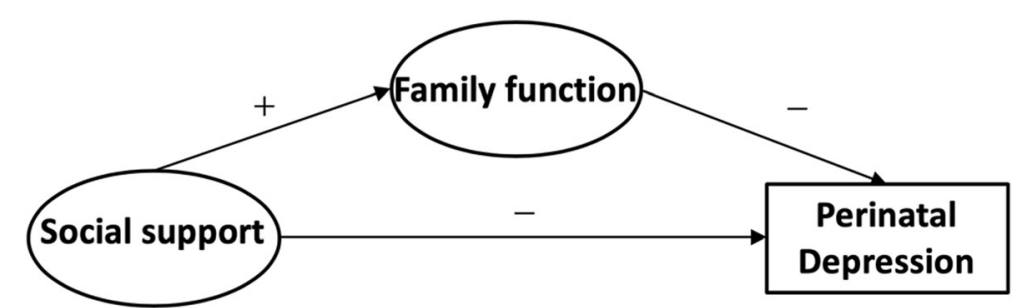

Fig. 1 The theoretical model and hypothesis

A multi-stage stratified random sampling was used to acquire the sample. In the first stage, we randomly chose a city in Sichuan province. In the second stage, we randomly selected a rural district in the city. In the third stage, 10 townships were randomly selected from the rural district. In the fourth stage, we randomly selected 50 maternal women from the database of maternal women established by each township hospital. Trained investigators invited the selected participants to take part in a face-to-face interview in their home and the questionnaires were completed by the investigators. We used the quantifiable scales, trained investigators, two-person data entry, and logical verification to ensure the quality of the research.

\section{Ethical considerations}

The study protocol was approved by the Institutional Review Board of Sichuan University (Project identification code: H171260). The study was explained by the trained investigators to participants and informed written consent was obtained within $10 \mathrm{~min}$ of consideration before data collection.

\section{Measures}

Participants' socio-demographic characteristics, social support, family function, and depression information were collected from questionnaires.

\section{Socio-demographic characteristics}

Socio-demographic characteristics included age, perinatal status, marital status, education level, employment status, individual annual income, medical insurance status, and complications of pregnancy.

\section{Social support}

Social support was assessed through the Social Support Rating Scale (SSRS), which was developed by Xiao (1994) [39]. The SSRS was specifically designed for use in a Chinese context and consists of ten items of three domains in total: objective support, subjective support, and social support utilization. Responses were provided as a 4-point Likert scale. The overall score of all items ranges from 12 to 66 with higher scores reflecting stronger social support. The total score has been divided into three levels: low (12-22), moderate (23-44), and high (45-66). The SSRS has been widely applied in China with excellent validity and reliability $[40,41]$. In this research, Cronbach's $\alpha$ of the scale was 0.825 .

\section{Family function}

Family function was measured by the APGAR, developed by Smilkstein [42], which was used to evaluate an individual's satisfaction with family function. This scale is a 3-point scale ranging from 0 (hardly ever) to 2 (almost always), composed of five items: adaptation, partnership, growth, affection and resolve. The total score ranges from 0 to 10 with higher scores denoting a higher level of satisfaction with family function. It is generally believed that scores of 0-3 indicate severe family dysfunction, scores of 4-6 indicate moderate family dysfunction, and scores of 7-10 indicate good family function. The Chinese version of APGAR has been widely applied in China with excellent validity and reliability [43, 44]. In this research, Cronbach's $\alpha$ of the scale was 0.874 .

\section{Depression}

Depression was measured by the Edinburgh Postnatal Depression Scale (EPDS). The EPDS, designed by Cox, et al. (1987) [45], was originally developed to assist primary care health professionals to detect mothers suffering from postpartum depression and was also proved to be suitable for the detection of antenatal depression in 2003 [46]. The EPDS is a 10-item self-reported questionnaire on depressive symptoms. Each item is scored on a 4-point scale (from 0 to 3 ), so that the total score ranges from 0 to 30, with higher scores representing more depressive symptoms. The EPDS was translated into a Chinese version by Pen et al. in 1994 [47], who recommended that the cut-off score for the Chinese was 9.5, and the score of 9.5 or higher indicates significant depressive symptoms. In this research, Cronbach's $\alpha$ of the scale was 0.776 .

\section{Statistical analyses}

The data were entered using the Epidata3.1 database and were analysed using SPSS version 20.0 (SPSS Inc., Chicago, IL, USA) and Analysis of Moment Structures 
(AMOS) version 24.0 (IBM, New York, NY, USA). First, we calculated descriptive statistics (frequencies, percentages, means, and standard deviations) to examine the socio-demographic characteristics of the sample. Second, we undertook a descriptive analysis of study variables (means and standard deviations). Third, binary logistic regression models were used to test the relationship between social support, family function, and depression. In model 1, we used depression as the dependent variable and social support, socio-demographic variables as independent variables. In model 2, we further added the family function as an independent variable. Fourth, a structural equation model (SEM) was employed to further test the hypothesis relationships among social support, family function, and perinatal depression.

The SEM used bootstrap maximum likelihood estimation and results with a $p$-value of $<0.05$ were considered statistically significant. To examine the model fit, we employed several indicators with their cut-offs: adjusted goodness of fit index (AGFI), a goodness of fit index (GFI), the comparative fit index (CFI), normed fit index (NFI), incremental (IFI), and Tucker-Lewis index (TLI) of 0.90 or above; a root mean squared error of approximation (RMSEA) less than or equal to 0.08 , indicated an acceptable model fit [48].

\section{Results}

\section{Participants and socio-demographic characteristics}

Of the 500 participants invited to take part, 498 agreed and returned questionnaires with a response rate of 99.6\%. Questionnaires were checked after the interviews for completeness. Eight records met exclusion criteria (Incomplete data collection: $n=2$; postpartum period $>6$ months $n=6$ ). Overall, 490 questionnaires were valid.

Socio-demographic characteristics of the 490 samples are shown in Table 1. The proportion of antenatal women and postpartum women were 50.8 and $49.2 \%$, respectively. The mean age (standard deviation) was $28.17 \pm 5.12$, ranging from 19 to 43 years. Most were married $(96.7 \%)$, educated at high school or vocational school level or less (73.7\%). The majority of the women were currently unemployed (57.3\%), had an individual annual income of less than $\$ 750$ (41.2\%), and held medical insurance (98.0\%). Most had no complications of pregnancy $(81.2 \%)$.

\section{Descriptive analysis of study variables}

Table 2 shows scores of social support, family function, and depression. The mean score (standard deviation) of social support was $40.79 \pm 5.95$ and $0.2 \%$ (1), $71.6 \%$ (351), and $28.2 \%$ (138) of participants had low, moderate, and high social support, respectively. The mean score (standard deviation) of family function was $8.80 \pm$ $1.89 ; 85.5 \%$ (419) of participants had good family
Table 1 Socio-demographic characteristics of the sample ( $n=$ 490)

\begin{tabular}{ll}
\hline Socio-Demographic Characteristics & $\boldsymbol{N}(\%)$ \\
\hline Age, mean \pm SD & $28.17 \pm 5.12$ \\
perinatal status & \\
$\quad$ Antenatal women & $249(50.8 \%)$ \\
Postpartum women & $241(49.2 \%)$ \\
Marital status & \\
$\quad$ Married & $474(96.7 \%)$ \\
Unmarried/ Divorced/ Widowed & $16(3.3 \%)$ \\
Education level & \\
Elementary and below & $31(6.3 \%)$ \\
Middle school & $141(28.8 \%)$ \\
High or vocational school & $189(38.6 \%)$ \\
College and above & $129(26.3 \%)$ \\
Employment status & \\
Employment & $209(42.7 \%)$ \\
Unemployed & $281(57.3 \%)$ \\
Individual annual income, (\$) & \\
$<750$ & $202(41.2 \%)$ \\
$750 \sim 1499$ & $68(13.9 \%)$ \\
1500 4499 & $122(24.9 \%)$ \\
$4500 \sim 7499$ & $73(14.9 \%)$ \\
Medical insurance 7500 & $25(5.1 \%)$ \\
No & \\
Yes & $10(2.0 \%)$ \\
$\quad$ Yes & $480(98.0 \%)$ \\
\hline
\end{tabular}

function while $13.1 \%$ (64) and $1.4 \%$ (7) of participants experienced moderate and severe family dysfunction, respectively. The mean score (standard deviation) of depression was $5.30 \pm 3.46$, and $10.4 \%$ (51) of women had significant depression symptoms. The mean score (standard deviation) of depression among antenatal and postpartum women were $5.78 \pm 3.30$ and $4.80 \pm 3.57$, respectively; $10.4 \%$ (26) of antenatal women and $10.4 \%$ (25) of postpartum women had significant depression symptoms. ANOVA showed that social support and family function were significantly correlated with depression symptoms.

\section{Binary logistic regression analyses of depression}

Table 3 shows the results of the binary logistic regression analyses testing the relationship between social support, family function, and depression. The results of model 1 suggest that there was no other factor except 
Table 2 Description of social support, family function scores with and without depression symptoms $(n=490)$

\begin{tabular}{lllll}
\hline Contents & Range & $\begin{array}{l}\text { Total } \\
\text { Mean (SD) }\end{array}$ & $\begin{array}{l}\text { Depression } \\
\text { (EPDS }<\text { 9.5, } \boldsymbol{n}=\mathbf{4 3 9}) \\
\text { Mean (SD) }\end{array}$ & $\begin{array}{l}\text { Non-depression } \\
\text { (EPDS } \geq \mathbf{9 . 5}, \boldsymbol{n}=\mathbf{5 1}) \\
\text { Mean (SD) }\end{array}$ \\
\hline Social support & $12-66$ & $40.79(5.95)$ & $38.76(5.40)$ & $41.03(5.97)$ \\
Objective support & $1-22$ & $9.8(2.21)$ & $9.06(2.10)$ & $9.89(2.20)$ \\
Subjective support & $8-32$ & $22.89(3.98)$ & $22.29(4.25)$ & $22.96(3.94)$ \\
Support utilization & $3-12$ & $8.10(1.70)$ & $7.41(1.64)$ & $8.18(1.69)$ \\
Family function & $0-10$ & $8.80(1.89)$ & $7.37(2.50)$ & $8.97(1.74)$ \\
Adaptation & $0-2$ & $1.77(0.45)$ & $1.43(0.57)$ & $1.81(0.42)$ \\
Partnership & $0-2$ & $1.74(0.48)$ & $1.43(0.57)$ & $1.77(0.46)$ \\
Growth & $0-2$ & $1.74(0.48)$ & $1.43(0.64)$ & $1.77(0.44)$ \\
Affection & $1.73(0.49)$ & $1.51(0.54)$ & $1.76(0.48)$ \\
Resolve & $0-2$ & $1.82(0.41)$ & $1.57(0.61)$ & $1.85(0.37)$ \\
Depression & $0-2$ & $5.30(3.46)$ & $11.76(3.18)$ & $4.55(2.61)$ \\
Antenatal & $0-30$ & $5.78(3.30)$ & $12.38(3.89)$ & $5.00(2.18)$ \\
Postpartum & $0-30$ & $4.80(3.57)$ & $11.12(2.11)$ & $4.07(2.92)$ \\
\hline
\end{tabular}

Notes: ** $p<0.05$

Table 3 Binary logistic regression of factors associated with the depression

\begin{tabular}{|c|c|c|c|c|c|c|}
\hline \multirow[t]{2}{*}{ Factors } & \multicolumn{3}{|l|}{ Model 1} & \multicolumn{3}{|l|}{ Model 2} \\
\hline & AOR & $p$-Value & $95 \% \mathrm{Cl}$ for $\mathrm{AOR}$ & AOR & $p$-Value & $95 \% \mathrm{Cl}$ for $\mathrm{AOR}$ \\
\hline Social support & 0.933 & $0.012^{* *}$ & $(0.884,0.985)$ & 0.945 & 0.060 & $(0.892,1.002)$ \\
\hline Family function & & & & 0.720 & $<0.001^{* *}$ & $(0.628,0.824)$ \\
\hline Age & 0.985 & 0.669 & $(0.919,1.056)$ & 0.992 & 0.830 & $(0.924,1.066)$ \\
\hline \multicolumn{7}{|c|}{ Perinatal status (ref: Antenatal women) } \\
\hline Postpartum women & 0.902 & 0.744 & $(0.484,1.680)$ & 1.130 & 0.713 & $(0.589,2.171)$ \\
\hline \multicolumn{7}{|l|}{ Marital status (ref: Married) } \\
\hline Unmarried/Divorced/Widowed & 0.607 & 0.573 & $(0.069,4.785)$ & 0.617 & 0.659 & $(0.072,5.257)$ \\
\hline \multicolumn{7}{|c|}{ Education level (ref: Elementary and below) } \\
\hline Middle school & 2.435 & 0.415 & $(0.287,20.662)$ & 2.797 & 0.357 & $(0.314,24.940)$ \\
\hline High or vocational school & 4.017 & 0.199 & $(0.482,33.489)$ & 4.790 & 0.158 & $(0.544,42.186)$ \\
\hline College and above & 3.837 & 0.220 & $(0.447,32.909)$ & 4.871 & 0.159 & $(0.537,44.192)$ \\
\hline \multicolumn{7}{|c|}{ Employment status (ref: Employment) } \\
\hline Unemployed & 1.200 & 0.580 & $(0.629,2.292)$ & 1.343 & 0.388 & $(0.688,2.624)$ \\
\hline \multicolumn{7}{|c|}{ Individual annual income (ref: <750, \$) } \\
\hline $750 \sim 1499$ & 0.690 & 0.483 & $(0.244,1.947)$ & 0.720 & 0.548 & $(0.247,2.099)$ \\
\hline $1500 \sim 4499$ & 1.320 & 0.458 & $(0.634,2.745)$ & 1.591 & 0.232 & $(0.743,3.406)$ \\
\hline $4500 \sim 7499$ & 0.967 & 0.944 & $(0.373,2.505)$ & 0.997 & 0.995 & $(0.373,2.661)$ \\
\hline$\geq 7500$ & 0.324 & 0.298 & $(0.039,2.708)$ & 0.342 & 0.361 & $(0.034,3.418)$ \\
\hline \multicolumn{7}{|l|}{ Medical insurance (ref: NO) } \\
\hline Yes & $144,344,517.3$ & 0.999 & $(0.000)$ & $98,701,368.48$ & 0.999 & 0.000 \\
\hline \multicolumn{7}{|l|}{ Complications of pregnancy (ref: No) } \\
\hline Yes & 1.484 & 0.273 & $(0.733,3.007)$ & 1.300 & 0.482 & $(0.626,2.701)$ \\
\hline
\end{tabular}

Notes: $A O R$ means adjusted odds ratio, ${ }^{* *} p<0.05$ 
for social support which was significantly correlated with depression (AOR $=0.933, p=0.012$ ). The results of model 2 suggest that only family function was significantly correlated with depression (AOR $=0.720, p<$ 0.001). According to the collinearity diagnosis, the VIF of each regression coefficient was no more than 2, the model fitted well. After controlling for the influence of family function, a previously significant relationship between social support and depression became nonsignificant, suggesting a full or perfect mediation relationship existed.

\section{Test of study model}

Figure 2 shows path analysis testing results of the fitness of the hypothetical model in Fig. 1. The final model had an adequate fit: $\mathrm{GFI}=0.960$, AGFI $=0.928, \mathrm{NFI}=0.934$, IFI $=0.951$, TLI $=0.928$, RMSEA $=0.075$.

The estimates for direct, indirect, and total effects with bias-corrected 95\% CI are shown in Table 4. In these analyses, effect coefficients are substantially significant if the $95 \%$ CI does not include 0 . The results showed that social support had a significant positive correlation with family function ( $\beta=0.293,95 \% \mathrm{CI}$ : 0.147 to 0.434 ), thus supporting Hypothesis 1 . However, the direct impact of social support on depression proved to be statistically non-significant ( $\beta=-0.090,95 \% \mathrm{CI}$ : -0.213 to 0.043 ), leading us to reject Hypothesis 2. The family function had a direct negative correlation with depression $(\beta=-$ 0.251 , 95\%CI: -0.382 to -0.118 ), thus supporting Hypothesis 3 . In addition, social support had an indirect negative correlation with depression $(\beta=-0.074,95 \% \mathrm{CI}$ : -0.139 to -0.032 ), thus supporting Hypothesis 4 .

Regarding the path between social support and depression, the total effect and indirect effect were statistically significant but the direct effect was statistically nonsignificant. Based on the above, family function fully mediates the relationship between social support and depression.

\section{Discussion}

This study aimed to investigate depression status and clarify the inter-relationships between social support and depression considering the influence of family function among perinatal women in rural areas of Southwest
China. To our knowledge, this is the first study to report the fully mediating role of family function between social support and perinatal depression. The findings of this study give important implications of development and implementation of interventions to ameliorate perinatal depression for mothers' health and to promote the future wellbeing of their children and families in rural areas.

The women in this study were investigated in communities and the prevalence of perinatal depression symptoms was $10.4 \%$, which is close to a previous metaanalysis which found a pooled prevalence of $10.7 \%$ in community settings [5]. In this meta study, the pooled prevalence in hospital settings was $17.6 \%$, which is higher than the prevalence in our study [5]. The reason may be that most studies in hospital settings reported women within 6 weeks postpartum. Women during the 6 weeks postpartum are required to engage in certain practices to promote the health of the maternal/newborn dyad for the Chinese tradition of "doing the month", mainly including promoting maternal rest, reducing domestic duties, and restricting activities at home [49]. To coerce a person into a certain behaviour, even if it is apparently for their good, is classified as negative and ineffective support [50]. Due to the limitation in physical and social activities, with frustrations around breastfeeding and lack of sleep which cannot be relieved effectively, women may be stressed which might lead to mood alterations [51]. After the first 6 weeks postpartum, with social activities resumed, women may accommodate and gradually accept their new situation [52].

The mean family function (APGAR) score was $8.80 \pm$ 1.89 , and only $1.4 \%$ of women reported severe family dysfunction in our study. A possible reason may be that in traditional rural China, pregnancy is regarded as a great familial contribution, and family members will acknowledge the women's family status and strive to develop better family function [53]. The model revealed that perinatal women with lower family function were more likely to experience depression symptoms, which is consistent with previous studies [32,54]. There are two possible explanations. One is that the couple relationship which plays an important role in family function will be affected in the perinatal period by more emerging work-

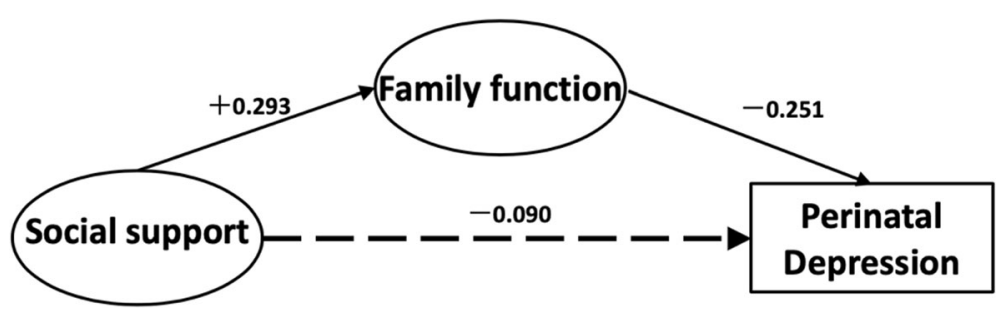

Fig. 2 The final model and standardized model paths 
Table 4 Direct, indirect and total effects and 95\% confidence intervals for the final model

\begin{tabular}{lll}
\hline Model pathways & Estimated effect & $\mathbf{9 5 \% C l}$ \\
\hline Total effects & & -0.274 to 0.028 \\
$\quad$ Depression <--- Social support & -0.164 & 0.147 to 0.434 \\
$\quad$ Family function <--- Social support & 0.293 & -0.382 to -0.118 \\
Depression <--- Family function & -0.251 & -0.213 to 0.043 \\
Direct effects & & 0.147 to 0.434 \\
Depression <--- Social support & -0.090 & -0.382 to -0.118 \\
Family function <--- Social support & 0.293 & -0.251 \\
$\quad$ Depression <--- Family function & & -0.139 to -0.032 \\
Indirect effects & -0.074 & \\
Depression <--- Social support & & \\
\hline
\end{tabular}

family and economic conflicts [55] and fewer opportunities for shared intimacy, which leads to women experiencing lower moods [56]. Another possible explanation is that women in dysfunctional families communicate their emotions and thoughts ineffectively with other family members, thus leading to the development of depression [57].

The results revealed that the mean score of social support among antenatal and postpartum women was $40.79 \pm 5.95$, which is lower than another study $(43.34 \pm$ 7.06) in China that surveyed women before pregnancy [58]. A possible reason may be that the women after pregnancy decrease physical exercise and leisure activities due to the concerns of maternal/child health, and thus receive less social support [59]. Our model revealed that better social support predicted better family function which is consistent with Jiang et al. (2015) study [60]. There are two possible reasons. One reason may be that social support improves an individual's physical health (for example, by increasing healthy activities and protective behaviours and promoting a healthier lifestyle) and ability to manage their stress and cope effectively; accordingly, the individual functions better within the family [61]. The other reason may be that the family members provide the most solid support in one's social network [62], partly owing to Chinese culture-specific norms of reciprocal filial piety [63], therefore, good social support means good family function in Chinese societies.

The most significant finding of this study was that the relationship between social support and depression was fully mediated by family function. Previous studies identified that social support had a direct effect on depression $[26,64]$, but this research further found the effect was indirect. Our model reveals that the higher social support among perinatal women was less likely to experience depression symptoms which is consistent with previous studies, but interestingly, the association was fully mediated by family function. The family function is the key factor. This can be explained by the vulnerability-stress model, when perinatal women facing the stressor, the low social support leads to family dysfunction which increases environmental vulnerability and triggers the onset of depression [65]. Compared to western women, Chinese women seem to be more family-oriented and thus are more likely to be affected by family relationships [33].

The findings of this study highlight the importance of family function in decreasing perinatal depression in rural areas and have important implications for public health practices. Healthcare professionals should pay more attention to evaluating family function constantly across the perinatal period and take a partner-inclusive intervention to lower the risk of perinatal depression [66]. Combining assessments like APGAR, especially applying the simple Resolve item-"Are you satisfied with the way you and your family share time together?"- can help professionals quickly assess family function [67]. For the dysfunctional family, health professionals should focus on interventions including family members in addition to perinatal women, such as requiring family members to participate in prenatal health and baby care education, providing different types of health education programs for different family members and setting up consulting platforms of perinatal nursing for families [68]. These are beneficial for minimizing the harmful effects of family dysfunction.

Limitations of this study need to be recognized. Firstly, we cannot make claims about causality among the three variables because of the cross-sectional design. Future longitudinal or experimental studies should be conducted to provide causal inference. Secondly, some factors such as life stress, personal history of depression, and family history of depression have not been taken into consideration, which may also influence the depression level of perinatal women. In addition, the EPDS is a screening tool rather than a diagnostic tool, which can only provide information on symptoms of depression. 
Finally, although our study concerned people in the community, which could reduce selection bias, the data was obtained in rural areas of southwest China, so we should be careful when generalizing findings.

\section{Conclusions}

This study investigates the interplay between social support and perinatal depression considering the influence of family function. Results suggest that family function plays a fully mediating role in the association between social support and depression. Findings of this study highlight that family function should be considered as the key target for interventions aiming to lower the prevalence of perinatal depression. Family members' interventions are critical to reducing perinatal depression.

\section{Abbreviations}

SEM: Structural equation modeling; EPDS: Edinburgh Postnatal Depression Scale; APGAR: APGAR Family Care Index Scale; SSRS: Social Support Rate Scale

\section{Supplementary Information}

The online version contains supplementary material available at https://doi. org/10.1186/s12888-021-03155-9.

Additional file 1. Perinatal Questionnaires.

Additional file 2. dataset(CSV 32KB).

\section{Acknowledgements}

The authors wish to acknowledge the help of all investigators who participated in our investigation, and are also thankful to all women participated in this project.

\section{Authors' contributions}

Conceptualization, Y.H., Y.L. D.L; Methodology, Y.H., Y.L.,D.L; Investigation, Y.L., D.L; Software, Y.H., Y.L.; Formal analysis, Y.H., Y.L.; Resources: D.L. Writing—original draft preparation, Y.H., Y.L.; Writing —review and editing, Y.H., Y.L., W. Y, D.L.. All authors read and approved the final manuscript.

\section{Funding}

None Declared.

\section{Availability of data and materials}

The datasets used and/or analysed during the current study available from the corresponding author on reasonable request.

\section{Declarations}

\section{Consent to publication}

Not applicable.

\section{Ethics approval and consent to participate}

The study protocol was approved by the Institutional Review Board of Sichuan University (Project identification code: H171260). The study was explained to participants and informed written consent was obtained prior to data collection.

\section{Competing interests}

The authors declare that they have no competing interests.

\section{Author details}

${ }^{1}$ West China School of Public Health and West China Fourth Hospital, Sichuan University, Chengdu 610041, China. ${ }^{2}$ Department of Radiation
Oncology, National Cancer Center and Cancer Hospital, Peking Union Medical College, Chinese Academy of Medical Sciences, Beijing, China.

Received: 27 July 2020 Accepted: 8 March 2021

Published online: 12 March 2021

References

1. Alipour Z, Lamyian M, Hajizadeh E. Anxiety and fear of childbirth as predictors of postnatal depression in nulliparous women. Women Birth. 2012;25(3):e37-43. https://doi.org/10.1016/j.wombi.2011.09.002.

2. Brummelte $S$, Galea LA. Postpartum depression: etiology, treatment and consequences for maternal care. Horm Behav. 2016;77:153-66. https://doi. org/10.1016/j.yhbeh.2015.08.008.

3. Goodman JH. Perinatal depression and infant mental health. Arch Psychiatr Nurs. 2019;33(3):217-24. https://doi.org/10.1016/j.apnu.2019.01.010.

4. Smith MV, Shao L, Howell H, Lin H, Yonkers KA. Perinatal depression and birth outcomes in a healthy start project. Matern Child Health J. 2011;15(3): 401-9. https://doi.org/10.1007/s10995-010-0595-6.

5. Nisar A, Yin J, Waqas A, Bai X, Wang D, Rahman A, Li X. Prevalence of perinatal depression and its determinants in mainland China: a systematic review and meta-analysis. J Affect Disord. 2020;277:1022-37. https://doi. org/10.1016/j.jad.2020.07.046.

6. Committee Opinion No ACOG. 757: screening for perinatal depression. Obstet Gynecol. 2018;132(5):e208-e12

7. Serati M, Redaelli M, Buoli M, Altamura AC. Perinatal major depression biomarkers: a systematic review. J Affect Disord. 2016;193:391-404. https:// doi.org/10.1016/j.jad.2016.01.027.

8. Piccinelli M, Wilkinson G. Gender differences in depression. Critical Rev Br J Psychiatry. 2000;177(6):486-92. https://doi.org/10.1192/bjp.177.6.486.

9. Meltzer-Brody S. New insights into perinatal depression: pathogenesis and treatment during pregnancy and postpartum. Dialogues Clin Neurosci. 2011;13(1):89-100

10. Jones I, Chandra PS, Dazzan P, Howard LM. Bipolar disorder, affective psychosis, and schizophrenia in pregnancy and the post-partum period. Lancet. 2014;384(9956):1789-99. https://doi.org/10.1016/S0140-6736(14)612 78-2.

11. Kendell RE, Wainwright S, Hailey A, Shannon B. The influence of childbirth on psychiatric morbidity. Psychol Med. 1976;6(2):297-302. https://doi.org/1 $0.1017 /$ S0033291700013854.

12. Lindahl V, Pearson $J$, Colpe $L$. Prevalence of suicidality during pregnancy and the postpartum. Arch Womens Ment Health. 2005;8(2):77-87. https:// doi.org/10.1007/s00737-005-0080-1.

13. Evans J, Heron J, Francomb H, Oke S, Golding J. Cohort study of depressed mood during pregnancy and after childbirth. BMJ (Clinical research ed). 2001;323(7307):257-60. https://doi.org/10.1136/bmj.323.7307.257.

14. Grote NK, Bridge JA, Gavin AR, Melville JL, lyengar S, Katon WJ. A metaanalysis of depression during pregnancy and the risk of preterm birth, low birth weight, and intrauterine growth restriction. Arch Gen Psychiatry. 2010; 67(10):1012-24. https://doi.org/10.1001/archgenpsychiatry.2010.111.

15. Hanko C, Bittner A, Junge-Hoffmeister J, Mogwitz S, Nitzsche K, Weidner K. Course of mental health and mother-infant bonding in hospitalized women with threatened preterm birth. Arch Gynecol Obstet. 2020;301(1):119-28. https://doi.org/10.1007/s00404-019-05406-3.

16. Dias CC, Figueiredo B. Breastfeeding and depression: a systematic review of the literature. J Affect Disord. 2015;171:142-54. https://doi.org/10.1016/j.jad.2 014.09.022.

17. Luoma I, Tamminen T, Kaukonen $\mathrm{P}$, Laippala P, Puura K, Salmelin R, et al. Longitudinal study of maternal depressive symptoms and child well-being. J Am Acad Child Adolesc Psychiatry. 2001;40(12):1367-74. https://doi.org/1 0.1097/00004583-200112000-00006.

18. Maeda Y, Ogawa K, Morisaki N, Tachibana Y, Horikawa R, Sago H. Association between perinatal anemia and postpartum depression: a prospective cohort study of Japanese women. Int J Gynaecol Obstet. 2020; 148(1):48-52. https://doi.org/10.1002/ijgo.12982.

19. Vesga-Lopez O, Blanco C, Keyes K, Olfson M, Grant BF, Hasin DS. Psychiatric disorders in pregnant and postpartum women in the United States. Arch Gen Psychiatry. 2008;65(7):805-15. https://doi.org/10.1001/archpsyc.65.7.805.

20. Jesse DE, Walcott-McQuigg J, Mariella A, Swanson MS. Risks and protective factors associated with symptoms of depression in low-income African American and Caucasian women during pregnancy. J Midwifery \& Women's Health. 2005;50(5):405-10. https://doi.org/10.1016/j.jmwh.2005.05.001. 
21. Martini J, Petzoldt J, Einsle F, Beesdo-Baum K, Hofler M, Wittchen HU. Risk factors and course patterns of anxiety and depressive disorders during pregnancy and after delivery: a prospective-longitudinal study. J Affect Disord. 2015;175:385-95. https://doi.org/10.1016/j.jad.2015.01.012.

22. Feldman R. Maternal versus child risk and the development of parent-child and family relationships in five high-risk populations. Dev Psychopathol. 2007;19(2):293-312. https://doi.org/10.1017/S0954579407070150.

23. Cohen S. Social relationships and health. Am Psychol. 2004;59(8):676-84. https://doi.org/10.1037/0003-066X.59.8.676.

24. Gariépy G, Honkaniemi H, Quesnel-Vallée A. Social support and protection from depression: systematic review of current findings in Western countries. $\mathrm{Br}$ J Psychiatry. 2016;209(4):284-93. https://doi.org/10.1192/bjp.bp.115.169094.

25. Li Y, Long Z, Cao D, Cao F. Social support and depression across the perinatal period: a longitudinal study. J Clin Nurs. 2017;26(17-18):2776-83. https://doi.org/10.1111/jocn.13817.

26. Robertson E, Grace S, Wallington T, Stewart DE. Antenatal risk factors for postpartum depression: a synthesis of recent literature. Gen Hosp Psychiatry. 2004;26(4):289-95. https://doi.org/10.1016/j.genhosppsych.2004.02.006.

27. Morikawa M, Okada T, Ando M, Aleksic B, Kunimoto S, Nakamura Y, Kubota C, Uno Y, Tamaji A, Hayakawa N, Furumura K, Shiino T, Morita T, Ishikawa N, Ohoka H, Usui H, Banno N, Murase S, Goto S, Kanai A, Masuda T, Ozaki N. Relationship between social support during pregnancy and postpartum depressive state: a prospective cohort study. Sci Rep. 2015;5(1):10520. https://doi.org/10.1038/srep10520.

28. Tarkka M-T, Paavilainen E, Lehti K, Åstedt-Kurki P. In-hospital social support for families of heart patients. J Clin Nurs. 2003;12(5):736-43. https://doi.org/1 0.1046/j.1365-2702.2003.00771.x

29. Lepistö S, Ellonen N, Helminen M, Paavilainen E. The family health, functioning, social support and child maltreatment risk of families expecting a baby. J Clin Nurs. 2017;26(15-16):2439-51. https://doi.org/10.1111/jocn.13 602.

30. Cao $X$, Jiang $X$, Li $X$, Hui Lo MC, Li R. Family functioning and its predictors among disaster bereaved individuals in China: eighteen months after the Wenchuan earthquake. PLoS One. 2013;8(4):e60738. https://doi.org/10.1371/ journal.pone.0060738.

31. Biaggi A, Conroy S, Pawlby S, Pariante CM. Identifying the women at risk of antenatal anxiety and depression: a systematic review. J Affect Disord. 2016; 191:62-77. https://doi.org/10.1016/j.jad.2015.11.014.

32. Lu C, Yuan L, Lin W, Zhou Y, Pan S. Depression and resilience mediates the effect of family function on quality of life of the elderly. Arch Gerontol Geriatr. 2017;71:34-42. https://doi.org/10.1016/j.archger.2017.02.011.

33. Hu Y, Wang Y, Wen S, Guo X, Xu L, Chen B, Chen P, Xu X, Wang Y. Association between social and family support and antenatal depression: a hospital-based study in Chengdu, China. BMC Pregnancy Childbirth. 2019; 19(1):420. https://doi.org/10.1186/s12884-019-2510-5.

34. Yan W, Sen L, Jinfeng Z, editors. The Relationship between Institutional Social Support and Depression in the Elderly Institutions: The Role of SelfTraining Perception and Family Function [in Chinese]. The 22nd National Conference on Psychology; 2019; Hangzhou, Zhejiang, China.

35. Patel V, Xiao S, Chen H, Hanna F, Jotheeswaran AT, Luo D, Parikh R, Sharma E, Usmani S, Yu Y, Druss BG, Saxena S. The magnitude of and health system responses to the mental health treatment gap in adults in India and China. Lancet. 2016 388(10063):3074-84. https://doi.org/10.1016/S0140-6736(16)00160-4.

36. Chen J, Cross WM, Plummer V, Lam L, Sun M, Qin C, Tang S. The risk factors of antenatal depression: a cross-sectional survey. J Clin Nurs. 2019;28(19-20): 3599-609. https://doi.org/10.1111/jocn.14955.

37. Wang $L$, Wu T, Anderson $J$, Florence JE. Prevalence and risk factors of maternal depression during the first three years of child rearing. J Women's Health (Larchmt). 2011;20(5):711-8. https://doi.org/10.1089/jwh.2010.2232.

38. Boyd RC, Le HN, Somberg R. Review of screening instruments for postpartum depression. Arch Womens Ment Health. 2005:8(3):141-53. https://doi.org/10.1007/s00737-005-0096-6.

39. Xiao S. The effect of social support on physical and psychological health. [in Chinese]. Chin. Psychiatry. 1994:98-100.

40. Cheng Y, Liu C, Mao C, Qian J, Liu K, Ke G. Social support plays a role in depression in Parkinson's disease: a cross-section study in a Chinese cohort. Parkinsonism Relat Disord. 2008;14(1):43-5. https://doi.org/10.1016/j.pa rkreldis.2007.05.011.

41. Xie R-H, He G, Koszycki D, Walker M, Wen SW. Prenatal social support, postnatal social support, and postpartum depression. Ann Epidemiol. 2009; 19(9):637-43. https://doi.org/10.1016/j.annepidem.2009.03.008.
42. Smilkstein $G$. The family APGAR: a proposal for a family function test and its use by physicians. J Fam Pract. 1978;6(6):1231-9.

43. Hai S, Wang H, Cao L, Liu P, Zhou J, Yang Y, Dong B. Association between sarcopenia with lifestyle and family function among community-dwelling Chinese aged 60 years and older. BMC Geriatr. 2017;17(1):187. https://doi. org/10.1186/s12877-017-0587-0.

44. Li C, Lu H, Qin W, Li X, Yu J, Fang F. Resilience and its predictors among Chinese liver Cancer patients undergoing Transarterial chemoembolization. Cancer Nurs. 2019;42(5):E1-e9. https://doi.org/10.1097/NCC. 0000000000000640

45. Cox JL, Holden JM, Sagovsky R. Detection of postnatal depression. Development of the 10-item Edinburgh postnatal depression scale. Br J Psychiatry. 1987;150(6):782-6. https://doi.org/10.1192/bjp.150.6.782.

46. Buist A. Perinatal mental health: a guide to the Edinburgh Postnatal Depression Scale. Archives of Women's Mental Health. 2004:7(1):96.

47. Wang Y, Guo X, Lau Y, Chan KS, Yin L, Chen J. Psychometric evaluation of the mainland Chinese version of the Edinburgh postnatal depression scale. Int J Nurs Stud. 2009;46(6):813-23. https://doi.org/10.1016/j.jinurstu.2009.01. 010.

48. Steiger $\mathrm{JH}$. Structural model evaluation and modification: an interval estimation approach. Multivar Behav Res. 1990;25(2):173-80. https://doi. org/10.1207/s15327906mbr2502_4.

49. Callister LC. Doing the month: Chinese postpartum practices. MCN Am J Matern Child Nurs. 2006;31(6):390. https://doi.org/10.1097/00005721-200611 000-00013.

50. França MS, Lopes MVO, Frazão C, Guedes TG, Linhares FMP, Pontes CM. Characteristics of the ineffective social support network: integrative review. Rev Gaucha Enferm. 2018:39:e20170303.

51. Tsai S-S, Wang $\mathrm{H}-\mathrm{H}$. Role changes in primiparous women during 'doing the month' period. Midwifery. 2019;74:6-13. https://doi.org/10.1016/j.midw.2019. 03.007

52. Prevalence and Risk Factors of Maternal Depression During the First Three Years of Child Rearing. Journal of Women's Health. 2011;20(5):711-8.

53. Liu YQ, Petrini M, Maloni JA. "Doing the month": postpartum practices in Chinese women. Nursing \& Health Sciences. 2015;17(1):5-14. https://doi. org/10.1111/nhs.12146

54. Wang J, Mansfield AK, Zhao X, Keitner G. Family functioning in depressed and non-clinical control families. Int J Soc Psychiatry. 2013;59(6):561-9. https://doi.org/10.1177/0020764012445260.

55. Shapiro AF, Gottman JM. Effects on marriage of a psycho-communicativeeducational intervention with couples undergoing the transition to parenthood, evaluation at 1-year post intervention. J Fam Commun. 2005; 5(1):1-24. https://doi.org/10.1207/s15327698jfc0501_1.

56. Fisher JR, Wynter $\mathrm{KH}$, Rowe HJ. Innovative psycho-educational program to prevent common postpartum mental disorders in primiparous women: a before and after controlled study. BMC Public Health. 2010;10(1):432. https:// doi.org/10.1186/1471-2458-10-432.

57. Wang Y, Tian L, Guo L, Huebner ES. Family dysfunction and Adolescents' anxiety and depression: a multiple mediation model. J Appl Dev Psychol. 2020;66:101090. https://doi.org/10.1016/j.appdev.2019.101090

58. Xu J, Chen P, Ma X. The relationship among preconception depression, anxiety, and social support of the reproductive-aged women in China. Arch Women's Mental Health. 2018:21(4):429-36. https://doi.org/10.1007/s00737-018-0817-2.

59. Nascimento SL, Surita FG, Godoy AC, Kasawara KT, Morais SS. Physical activity patterns and factors related to exercise during pregnancy: a Cross sectional study. PLoS One. 2015;10(6):e0128953. https://doi.org/10.1371/ journal.pone.0128953.

60. Jiang H, Wang L, Zhang Q, Liu DX, Ding J, Lei Z, Lu Q, Pan F. Family functioning, marital satisfaction and social support in hemodialysis patients and their spouses. Stress Health. 2015;31(2):166-74. https:/doi.org/10.1002/smi.2541.

61. Shamali M, Konradsen H, Stas L, Østergaard B. Dyadic effects of perceived social support on family health and family functioning in patients with heart failure and their nearest relatives: using the actor-partner interdependence mediation model. PLoS One. 2019;14(6):e0217970. https:// doi.org/10.1371/journal.pone.0217970.

62. Li T, Guo N, Jiang H, Eldadah M, Zhuang W. Social support and second trimester depression. Midwifery. 2019;69:158-62. https://doi.org/10.1016/j. midw.2018.11.012

63. Bedford $\mathrm{O}$, Yeh $\mathrm{KH}$. The history and the future of the psychology of filial piety: Chinese norms to contextualized personality construct. Front Psychol. 2019;10:100. https://doi.org/10.3389/fpsyg.2019.00100. 
64. Racine N, Zumwalt K, McDonald S, Tough S, Madigan S. Perinatal depression: the role of maternal adverse childhood experiences and socia support. J Affect Disord. 2020;263:576-81. https://doi.org/10.1016/j.jad.201 9.11.030.

65. Bernazzani O, Marks MN, Bifulco A, Siddle K, Asten P, Conroy S. Assessing psychosocial risk in pregnant/postpartum women using the contextual assessment of maternity experience (CAME)--recent life adversity, social support and maternal feelings. Soc Psychiatry Psychiatr Epidemiol. 2005: 40(6):497-508. https://doi.org/10.1007/s00127-005-0917-y.

66. Alves S, Martins A, Fonseca A, Canavarro MC, Pereira M. Preventing and treating Women's postpartum depression: a qualitative systematic review on partner-inclusive interventions. J Child Fam Stud. 2018;27(1):1-25. https://doi.org/10.1007/s10826-017-0889-z.

67. Takenaka $\mathrm{H}$, Ban N. The most important question in family approach: the potential of the resolve item of the family APGAR in family medicine. Asia Pac Family Med. 2016;15:3.

68. Tang X, Lu Z, Hu D, Zhong X. Influencing factors for prenatal stress, anxiety and depression in early pregnancy among women in Chongqing, China. J Affective Disorders. 2019;253:292-302. https://doi.org/10.1016/j.jad.2019.05. 003.

\section{Publisher's Note}

Springer Nature remains neutral with regard to jurisdictional claims in published maps and institutional affiliations.

Ready to submit your research? Choose BMC and benefit from:

- fast, convenient online submission

- thorough peer review by experienced researchers in your field

- rapid publication on acceptance

- support for research data, including large and complex data types

- gold Open Access which fosters wider collaboration and increased citations

- maximum visibility for your research: over $100 \mathrm{M}$ website views per year

At $\mathrm{BMC}$, research is always in progress.

Learn more biomedcentral.com/submissions 